\title{
The LuxR receptor: the sites of interaction with quorum-sensing signals and inhibitors
}

\section{Correspondence \\ Michael Givskov \\ immg@pop.dtu.dk}

Received 9 February 2005

Revised 20 May 2005

Accepted 8 July 2005

\author{
B. Koch, ${ }^{1}$ T. Liljefors, ${ }^{2}$ T. Persson, ${ }^{3}$ J. Nielsen, ${ }^{3}$ S. Kjelleberg ${ }^{4}$ \\ and M. Givskov ${ }^{1}$
}
${ }^{1}$ Center for Biomedical Microbiology, BioCentrum-DTU, Building 301, Technical University of Denmark, DK-2800 Lyngby, Denmark
${ }^{2}$ Department of Medicinal Chemistry, The Danish University of Pharmaceutical Sciences, Universitetsparken 2, DK-2100 Copenhagen Ø, Denmark
${ }^{3}$ Department of Natural Sciences, The Royal Veterinary and Agricultural University, Thorvaldsensvej 40, DK-1871 Frederiksberg C, Denmark
${ }^{4}$ School of Biotechnology and Biomolecular Science and Centre for Marine Biofouling and Bio-innovation, Biological Science Building, University of New South Wales, Randwick, Sydney, NSW 2052, Australia

The function of LuxR homologues as quorum sensors is mediated by the binding of $\mathrm{N}$-acyl-L-homoserine lactone (AHL) signal molecules to the $\mathrm{N}$-terminal receptor site of the proteins. In this study, site-directed mutagenesis was carried out of the amino acid residues comprising the receptor site of LuxR from Vibrio fischeri, and the ability of the L42A, L42S, Y62F, W66F, D79N, W94D, V109D, V109T and M135A LuxR mutant proteins to activate green fluorescent protein expression from a $P_{l u x l}$ promoter was measured. X-ray crystallographic studies of the LuxR homologue TraR indicated that residues $\mathrm{Y} 53$ and W57 form hydrogen bonds to the 1-carbonyl group and the ring carbonyl group, respectively, of the cognate $\mathrm{AHL}$ signal. Based on the activity and signal specificity of the LuxR mutant proteins, and on molecular modelling, a model is suggested in which Y62 (corresponding to Y53 in TraR) forms a hydrogen bond with the ring carbonyl group rather than the 1-carbonyl group, while W66 (corresponding to W57 in TraR) forms a hydrogen bond to the 1-carbonyl group. This flips the position of the acyl side chain in the LuxR/signal molecule complex compared to the TraR/signal molecule complex. Halogenated furanones from the marine alga Delisea pulchra and the synthetic signal analogue $N$-(sulfanylacetyl)-L-homoserine lactone can block quorum sensing. The LuxR mutant proteins were insensitive to inhibition by $\mathrm{N}$-(propylsulfanylacetyl)-L-homoserine lactone. In contrast, the mutations had only a minor effect on the sensitivity of the proteins to halogenated furanones, and the data strongly suggest that these compounds do not compete in a 'classic' way with $N$-3-oxohexanoyl-L-homoserine lactone for the binding site. Based on modelling and experimental data it is suggested that these compounds bind in a non-agonist fashion.

\section{INTRODUCTION}

Many bacteria employ a cell-cell signalling system to control expression of target genes in response to population size in a process known as quorum sensing. Among Gramnegative bacteria, quorum sensing is often mediated by

Abbreviations: $\mathrm{AHL}, \mathrm{N}$-acyl-L-homoserine lactone; $\mathrm{BHL}, \mathrm{N}$-butanoyl-Lhomoserine lactone; GFP, green fluorescent protein; HHL, $N$-hexanoyl$\mathrm{DL}$-homoserine lactone; $\mathrm{OHHL}, \mathrm{N}$-3-oxohexanoyl-L-homoserine lactone; $\mathrm{OHL}, \mathrm{N}$-octanoyl-DL-homoserine lactone; OOHL, N-3-oxooctanoyl-Lhomoserine lactone; PenS-AHL, $\mathrm{N}$-(pentylsulfanylacetyl)-L-homoserine lactone; ProS-AHL, N-(propylsulfanylacetyl)-L-homoserine lactone.

A table with the sequences of the mutagenic oligonucleotides is available as supplementary material with the online version of this paper.
$\mathrm{N}$-acyl-L-homoserine lactone (AHL) signal molecules. These molecules are frequently referred to as autoinducers. Depending on the bacterial species, these molecules differ in the length of their acyl side chain (4-18 carbons) (Marketon et al., 2002). Furthermore, the chain can be unsaturated and it often contains an oxo or hydroxyl group substitution on the third carbon atom (Whitehead et al., 2001). AHLs are generally believed to bind to and activate receptor proteins. The receptor protein functions as a cytoplasmic transcriptional activator or repressor (Minogue et al., 2002; Whitehead et al., 2001). These proteins, of which LuxR is the prototype, show overlapping signal specificity, where compounds closely related to the cognate signal can function as agonists causing weak to moderate gene expression, 
whereas other signal analogues can function as antagonists of the native autoinducer (Schaefer et al., 1996; Zhu et al., 1998).

A number of studies have been carried out with mutated forms of LuxR-type proteins (Chai \& Winans, 2004; Choi \& Greenberg, 1991; Hanzelka \& Greenberg, 1995; Kiratisin et al., 2002; Lamb et al., 2003; Luo et al., 2003a; Shadel et al., 1990; Slock et al., 1990), and the crystal structure of the LuxR homologue TraR of Agrobacterium tumefaciens in complex with $\mathrm{N}$-3-oxooctanoyl-L-homoserine lactone (OOHL) and DNA has been solved (Vannini et al., 2002; Zhang et al., 2002). This has led to the general assumption that the $\mathrm{N}$-terminal domain of LuxR-type proteins binds the signal molecule (Hanzelka \& Greenberg, 1995; Kiratisin et al., 2002; Lamb et al., 2003; Vannini et al., 2002; Zhang et al., 2002), while the C-terminal domain is involved in DNA binding (Choi \& Greenberg, 1991; Kiratisin et al., 2002; Lamb et al., 2003; Vannini et al., 2002; Zhang et al., 2002). Despite sequence similarity in the signal-binding region, biochemical evidence suggests that the various LuxR homologues exhibit differences in autoinducer accessibility. In TraR, the signal molecule is completely embedded into a narrow cavity devoid of solvent contact (Vannini et al., 2002; Zhang et al., 2002). This is in accordance with the observations that removal of OOHL from the TraR-OOHL complex requires extensive dialysis in the presence of detergent (Zhu \& Winans, 1999), and that TraR activated by OOHL or $\mathrm{N}$-3-oxohexanoyl-L-homoserine lactone (OHHL) remains active for as long as $8 \mathrm{~h}$ after removal of exogenous signal (Luo et al., 2003b). In contrast, experiments with the purified LuxR protein show that the LuxR-OHHL complex can be reversibly inactivated by dilution, suggesting a weaker binding of the signal molecule (Urbanowski et al., 2004). The LuxR homologue EsaR of Pantoea stewartii functions as a repressor, and the addition of signal triggers the release of the protein from DNA (Minogue et al., 2002). The LuxR homologue RhlR of Pseudomonas aeruginosa has recently been reported to bind to the rhlAB las box both in the absence and in the presence of the AHL signal serving as a repressor and an activator, respectively (Medina et al., 2003). The receptivity of these apo-proteins to their signal molecules indicates that their signal binding site must be highly accessible.

In most cases, quorum-sensing systems control the expression of virulence genes and biofilm development, traits that are important for the interaction with and colonization of eukaryotic hosts (Smith \& Iglewski, 2003). This includes the regulation of virulence factors in human pathogens such as P. aeruginosa (Hentzer et al., 2003; Wagner et al., 2003; Schuster et al., 2003) and Yersinia pseudotuberculosis (Atkinson et al., 1999), factors involved in food spoiling mediated by serratia strains (Christensen et al., 2003) and virulence factors of plant-pathogenic bacteria such as Erwinia carotovora (Whitehead et al., 2002).

As interference with AHL-mediated gene expression offers an opportunity to control unwanted microbial activity without the use of growth-inhibitory agents, which select for resistant organisms, much work has been carried out to identify synthetic analogues of AHLs that function as AHL antagonists (Smith et al., 2003; Olsen et al., 2002). In nature, algae and higher plants have been found to produce substances that inhibit AHL-regulated behaviour (Givskov et al., 1996; Bauer \& Robinson, 2002). While the compounds responsible for this activity in higher plants have not yet been identified (Bauer \& Robinson, 2002), several halogenated furanones that inhibit AHL-controlled processes have been isolated from the marine red alga Delisea pulchra (de Nys et al., 1993). Regarding the mechanism of action, several data sets show that halogenated furanones interact specifically with LuxR from Vibrio fischeri (Manefield et al., 1999, 2002).

In the present report, we characterize the influence of selected amino acid substitutions on the interaction between LuxR, signal molecules, signal antagonists and quorumsensing inhibitors. Based on this, we propose a model for the binding modes of the molecules in the LuxR receptor site.

\section{METHODS}

Strains and culture conditions. The Escherichia coli XL1-Blue strain (Stratagene) was grown in Luria-Bertani (LB) broth (containing $10 \mathrm{~g} \mathrm{NaCl}^{-1}$ ) or in minimal $\mathrm{ABT}$ medium [AB minimal medium (Clark \& Maaløe, 1967) containing $2.5 \mathrm{mg}$ thiamine $\mathrm{l}^{-1}$ ] at 30 or $37^{\circ} \mathrm{C}$. A. tumefaciens NT1 (Cha et al., 1998) was grown in LB broth (containing $10 \mathrm{~g} \mathrm{NaCl}^{-1}$ ) at $28^{\circ} \mathrm{C}$. Antibiotics were added to liquid or solid media at the following concentrations as appropriate: $100 \mu \mathrm{g}$ ampicillin $\mathrm{ml}^{-1}, 30 \mu \mathrm{g}$ chloramphenicol $\mathrm{ml}^{-1}, 8 \mu \mathrm{g}$ tetracycline $\mathrm{ml}^{-1}$ and $20 \mu \mathrm{g}$ gentamicin $\mathrm{ml}^{-1}$.

Mutagenesis and plasmid construction. Recent data indicate that the translation of LuxR is initiated at an ATG codon situated $6 \mathrm{bp}$ upstream of the originally proposed start codon (Urbanowski et al., 2004). To facilitate the comparison with previously published LuxR mutants we have decided to keep the previous numbering of the residues. Site-directed mutations were introduced into the luxR gene from $V$. fischeri encoded by the plasmid pJBA89 (Andersen et al., 2001). All mutations were created by overlap extension PCR (Ho et al., 1989). The sequences of the mutagenic oligonucleotides are shown in the Supplementary Table available with the online journal. PCR was performed with the Expand High Fidelity PCR system (Roche Diagnostics). Except for the PCR products used to create the mutants pJBA89L42A and pJBA89L42S, the overlap extension products were digested with EcoRI and XbaI. The resulting 585 bp fragments were cloned into pJBA89 digested with EcoRI and XbaI, using standard cloning techniques (Sambrook et al., 1989). The overlap extension products used to create pJBA89L42A and pJBA89L42S were digested with EcoRI and KpnI. The resulting 996 bp fragments were cloned into pJBA89 digested with EcoRI and KpnI. All mutations were verified by sequencing, which was carried out by GATC Biotech. Primers for sequencing and PCR were obtained from TAG Copenhagen.

Determination of green fluorescent protein (GFP) expression. The LuxR-controlled green-fluorescent-AHL monitor strain $E$. coli XL1-Blue(pJBA89), which carries $l u x R^{+}$and a $P_{l u x I^{-}} g f p(\mathrm{ASV})$ fusion (Andersen et al., 2001), or the strain containing a selection of pJBA89 derivative plasmids with mutations in $l u x R$, was cultured in 
ABT minimal medium. To obtain exponentially growing cultures minimal ABT medium was inoculated from overnight cultures to an initial $\mathrm{OD}_{600}$ of 0.05 and grown for $4-5 \mathrm{~h}$ at $30^{\circ} \mathrm{C}$.

For GFP measurements, aliquots of exponential phase E. coli XL1-Blue cultures carrying pJBA89 with or without mutations in $\operatorname{luxR}$ were distributed to the wells of microtitre dishes in which different AHLs, AHL analogues or OHHL in combination with quorum-sensing inhibitors at the required concentrations were already present. Every $15 \mathrm{~min}$ for $2 \mathrm{~h}$, the relative units of fluorescence (RFU) of each sample were measured with a Wallac Victor2, 1420 Multilabel Counter using a $485 \mathrm{~nm}$ excitation filter and a $535 \mathrm{~nm}$ emission filter. The $\mathrm{OD}_{450}$ was also measured for each sample in order to determine cell-specific fluorescence. This cell-specific fluorescence was plotted versus time, and the linear part of the curve was used for linear regression to obtain the change in cell-specific GFP expression versus time. All measurements were repeated at least twice.

Antagonist preparation. The halogenated furanones C-2 and C-56 were synthesized as previously described (Manny et al., 1997). The halogenated furanone C-4 was extracted from D. pulchra and purified by HPLC according to protocols established by de Nys et al. (1993). The halogenated furanone C-30 was synthesized according to protocols reported by Wells (1963). $\mathrm{N}$-(propylsulfanylacetyl)-Lhomoserine lactone (ProS-AHL) and $\mathrm{N}$-(pentylsulfanylacetyl)-Lhomoserine lactone (PenS-AHL) were synthesized as described previously by Persson et al. (2005).

\begin{abstract}
Western blotting. In order to measure GFP expression and perform Western blotting under identical conditions, we originally grew our E. coli XL1-Blue(pJBA89) cultures in ABT minimal medium at $30^{\circ} \mathrm{C}$. Unfortunately very low levels of LuxR were produced in this medium compared to growth in LB broth, as judged by Western blotting (data not shown). Use of LB caused a higher background than use of ABT minimal medium in our GFP measurements (data not shown). There was significantly more LuxR protein present in cells grown at $37^{\circ} \mathrm{C}$ compared to cells grown at $30^{\circ} \mathrm{C}$. For Western blotting of the LuxR proteins we therefore used either the E. coli XL1-Blue cells harbouring pJBA89 with or without $l u x R$ mutations grown in $\mathrm{LB}$ at $37^{\circ} \mathrm{C}$ to $\mathrm{OD}_{600} 1-1 \cdot 5$, or E. coli XL1-Blue cells carrying the $P_{\text {tac }}$-luxR expression plasmid pHK724 (Kaplan \& Greenberg, 1987 ) and pGroESL (Goloubinoff et al., 1989) grown in LB at $37^{\circ} \mathrm{C}$ to $\mathrm{OD}_{600} 0 \cdot 3-0 \cdot 4$ in the presence of $100 \mu \mathrm{M}$ of the inducer IPTG. Based on four Western blots of proteins from cells with pJBA89 with or without $\operatorname{luxR}$ mutations, and numerous Western blots with E. coli XL1-Blue(pHK724)(pGroESL), we concluded that the highest reproducibility was obtained with E. coli XL1-Blue(pHK724)(pGroESL). This strain was therefore selected for quantitative measurements.
\end{abstract}

Cells carrying pHK724 and pGroESL were harvested by centrifugation at $10000 \mathrm{~g}$, at $4{ }^{\circ} \mathrm{C}$ for $5 \mathrm{~min}$, washed once and then resuspended in an equal volume of fresh medium. Various concentrations of halogenated furanones and/or OHHL were added to aliquots of washed cells resuspended in fresh medium, and the samples were incubated at $37^{\circ} \mathrm{C}$ for 0.5 or $1 \mathrm{~h}$. After the treatment, samples were frozen immediately and kept at $-20{ }^{\circ} \mathrm{C}$. Samples of E. coli XL1-Blue cells carrying pJBA89, or pJBA89 derivatives with mutations in $\operatorname{luxR}$, were taken directly from growing cultures and frozen. Prior to SDS-PAGE, the samples were adjusted to similar $\mathrm{OD}_{600}$ values. Western blots of the separated proteins were incubated with an anti-LuxR antibody from Quorum Sciences as the primary antibody, and an anti-rabbit horseradishperoxidase-conjugated antibody from Amersham as the secondary antibody, according to the manufacturer's recommendations. Localization of the secondary antibody was visualized using chemiluminescent detection reagents from Amersham and a Hamamatsu C2400-47 double intensified CCD camera. Colour images were saved in 16-bit format (the scale has a resolution of 16 colours) using ARGUS-50 software (Hamamatsu).

Molecular modelling. Our model of the AHL binding site in LuxR is based on the crystal structure of TraR from A. tumefaciens in complex with OOHL and DNA (PDB code 1L3L) (Zhang et al., 2002). Due to the low overall homology of TraR and LuxR, the modelling was restricted to the binding-site region defined by a sphere with a radius of $12 \AA$ centred on the 3-carbonyl group of OOHL. The amino acid residues in TraR that are different from those of LuxR, according to the alignment by Whitehead et al. (2001), were replaced by the corresponding ones of LuxR using the program InsightII (Accelrys). The rotamer option in InsightII was then used to find the energetically most favourable conformations of the side chains. The calculations of the size, shape and the burial extent of the binding sites of TraR and LuxR were performed with the program PASS (Putative Active Sites with Spheres) developed by Brady \& Stouten (2000).

\section{RESULTS AND DISCUSSION}

\section{Initial model for the molecular interaction between LuxR and halogenated furanones}

Because of the structural similarities between AHL molecules and the halogenated furanones from D. pulchra, it has been hypothesized that the mode of action of these molecules is competitive (Givskov et al., 1996). Studies of the interactions between halogenated furanones and LuxR homologues have focused on LuxR from $V$. fischeri (Manefield et al., 1999, 2002) but halogenated furanones also inhibit quorum-sensing-controlled phenotypes in Serratia liquefaciens (Givskov et al., 1996), $V$. harveyi (Manefield et al., 2000), Erwinia carotovora (Manefield et al., 2001) and Chromobacterium violaceum (Martinelli et al., 2004). Despite functional promiscuity, the natural furanones showed a limited effect on a LasR-controlled AHL biosensor (Hentzer et al., 2002). This biosensor did, however, show sensitivity to the synthetic halogenated furanones C-56 (Hentzer et al., 2002) and C-30 (Hentzer et al., 2003). Both are devoid of the alkyl side chain present in the natural compounds (Fig. 1). Analysis using the TraR-controlled AHL biosensor pZLR4 in A. tumefaciens indicated that halogenated furanones had a very limited effect on the TraR quorum sensor when tested in concentrations that did not affect growth (data not shown).

To further investigate on the interaction between LuxR and antagonists, we carried out site-directed mutagenesis of the luxR gene present on the LuxR-controlled AHL sensor pJBA89 (Andersen et al., 2001). If halogenated furanones function as competitive inhibitors as has been suggested (Givskov et al., 1996) they would be expected to bind to LuxR in a mode similar to the binding of the signal molecule, and the binding would be expected to involve at least some of the amino acid residues that are involved in OHHL binding. The X-ray structure of the LuxR homologue TraR complexed with OOHL and DNA has provided information about the amino acids residues involved in signal binding (Zhang et al., 2002; Vannini et al., 2002). 
$N$-acyl-L-homoserine lactones<smiles>CCCC(=O)CC(=O)NC1CCCO1</smiles>

OHHL<smiles>CCCCCC(=O)CC(=O)N[C@H]1CCOC1=O</smiles>

OOHL<smiles>CCCCCC(=O)N[C@H]1CCOC1=O</smiles>

HHL<smiles>CCCCCCCC(=O)NC1CCOC1=O</smiles>

OHL
$N$-(sulfanylacetyl)-L-homoserine lactones<smiles>CCCCCSCC(=O)N[C@H]1CCOC1=O</smiles>

PenS-AHL<smiles>CCCSCC(=O)N[C@H]1CCOC1=O</smiles>

ProS-AHL
Halogenated furanones
$\mathrm{C}-2$<smiles></smiles><smiles></smiles>

C-4<smiles>O=C1C=C(Br)C(=CBr)O1</smiles>

C-30<smiles></smiles>

C-56
Fig. 1. AHLs, $A H L$ analogues and halogenated furanones used in this study.

Although the overall homology between the LuxR-type proteins is low, there are several highly conserved residues, which are thought to be involved in AHL binding. Of the nine TraR residues identified by Vannini et al. (2002) surrounding the homoserine lactone moiety of OOHL, five are identical and two are conserved in LuxR, while the residues involved in hydrophobic interaction with the acyl chain are less conserved. Furthermore, of the 18 residues positioned in close proximity to OOHL in the TraR-OOHL complex, 9 are conserved in LuxR. We therefore considered the TraR binding site as an initial model for the interaction of signal molecules and inhibitors with LuxR.

In order to select residues for site-directed mutagenesis, furanone C-30 was superimposed on OOHL bound to TraR by molecular modelling, and amino residues situated close to C-30 and/or OOHL were identified (Fig. 2). The residues Y53, W57 and D70 of TraR form hydrogen bonds to the 1-carbonyl group, the ring carbonyl group and the $\mathrm{NH}$ group of OOHL, respectively (Zhang et al., 2002). These three residues are highly conserved in LuxR-type proteins (Table 1). According to this putative model of furanone binding, the TraR residue W57 would be expected to form hydrogen bonds to the ring carbonyl group of C-30, while

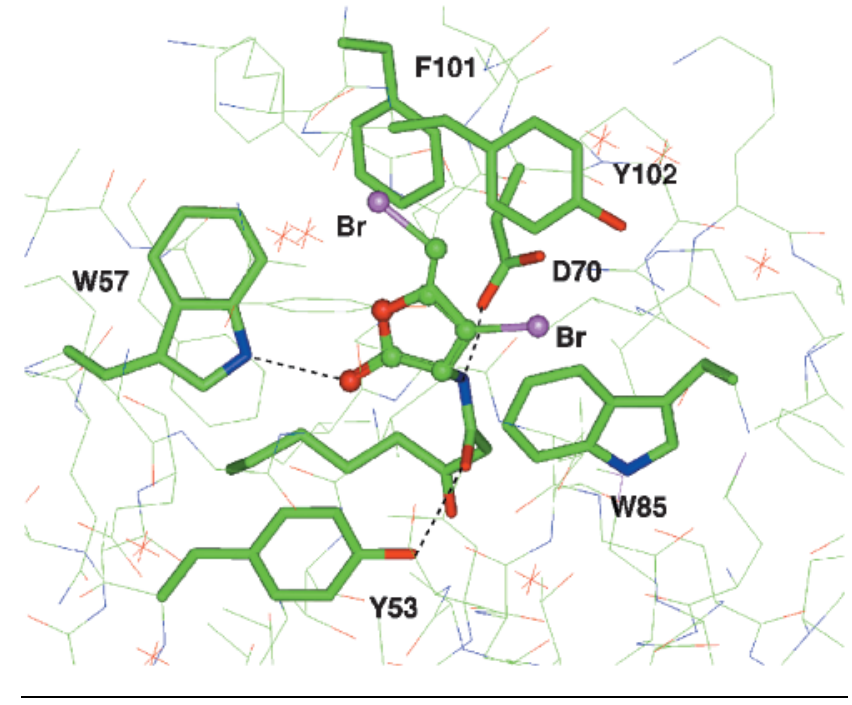

Fig. 2. Initial model for $\mathrm{C}-30$ binding. Molecular superimposition of $\mathrm{C}-30$ on $\mathrm{OOHL}$ in the TraR binding site. Our experimental data did not verify this model for binding of halogenated furanones.

the TraR residues D70 and Y53 cannot since halogenated furanones lack the $\mathrm{NH}$ group and the 1-carbonyl group present in AHLs (Fig. 1). Since we used the TraR-furanone interaction as a model for the LuxR-furanone interaction, the residues in LuxR corresponding to the above-mentioned TraR residues were identified and subjected to site-directed mutagenesis. The LuxR Y62 residue (corresponding to Y53 in TraR) was changed to phenylalanine, which structurally resembles tyrosine but is unable to form hydrogen bonds. The W66 residue (corresponding to W57 in TraR) was changed to histidine, while D79 (corresponding to D70 in TraR) was changed to asparagine, changes which do not abolish the ability to form hydrogen bonds.

Despite the obvious similarity in the signal-binding region of LuxR-type proteins, there are also important differences. According to Vannini et al. (2002), F101 and Y102 in TraR are situated above the lactone ring (Fig. 2) where they are part of the cavity surrounding the homoserine moiety of the AHL molecule. F101 and Y102 are not highly conserved in LuxR homologues. The alignment of 29 LuxR homologues by Whitehead et al. (2001) shows that F101 does align with other hydrophobic residues but often aligns with aliphatic residues (10 valine, 7 isoleucine, 6 leucine). In most cases, Y102 aligns with aromatic residues (14 phenylalanine, 7 tryptophan, 2 tyrosine out of 29). The substitutions of F101 and Y102 with V109 and I110 in LuxR result in a more open structure in this region, as shown by the calculated size and shape of the binding sites of TraR and the LuxR model as depicted in Fig. 3. This is in agreement with the observation that the cognate signal molecule of LuxR is more exposed to the solvent than the cognate signal molecule of TraR (Urbanowski et al., 2004). By means of the superimposition 
Table 1. AHL activation of mutagenized LuxR molecules

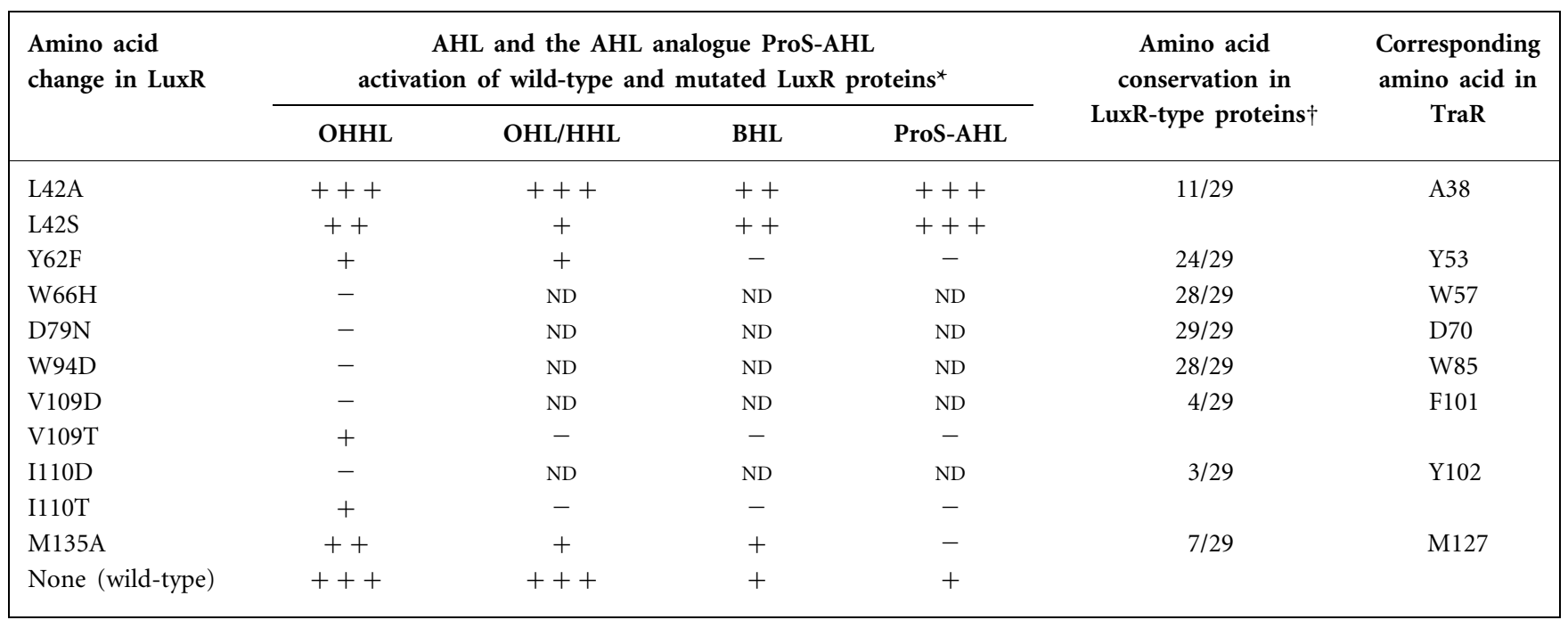

${ }^{\star}$ The concentration of AHL needed to fully activate LuxR-dependent GFP expression from the luxI promoter is indicated by,+++++ and + for low, medium and high concentration, respectively. - indicates that LuxR cannot be activated by exogenously added AHL signals. These columns summarize the data presented in Fig. 4 (for OHHL, OHL, HHL and BHL) and Fig. 8(b) (for ProS-AHL). ND, Not determined.

$\dagger$ The numbers indicate the number of LuxR-type proteins out of 29 with an amino acid identical to LuxR. The numbers are based on the alignment performed by Whitehead et al. (2001).

presented in Fig. 2, F101 and Y102 of TraR were identified as residues in the proximity of bromine atom 1 of C-30 while W85 was situated close to bromine atom 2 . Since brominecarbon bonds display polarity with a partial negative charge surrounding the bromine atom, we assumed that a negatively charged or a polar side chain present on residues situated close to halogenated furanones would repel and cause insensitivity to the inhibitor. We therefore changed W94, V109 and I110 in LuxR to aspartic acid. In addition, V109 and I110 were both changed to a threonine.

\section{Activity of the LuxR mutants}

The AHL sensor pJBA89 carries $l u x R$ and a $P_{l u x I^{-}} g f p$ (ASV) fusion that encodes an unstable version of GFP (Andersen et al., 2001). In the presence of OHHL, LuxR activates the transcription of the gene fusion from the $P_{l u x I}$ promoter. After introduction of site-directed mutations into $l u x R$, the activities of the mutated proteins were determined from the level of OHHL-dependent GFP expression. Measurements were performed for all the mutant proteins at OHHL
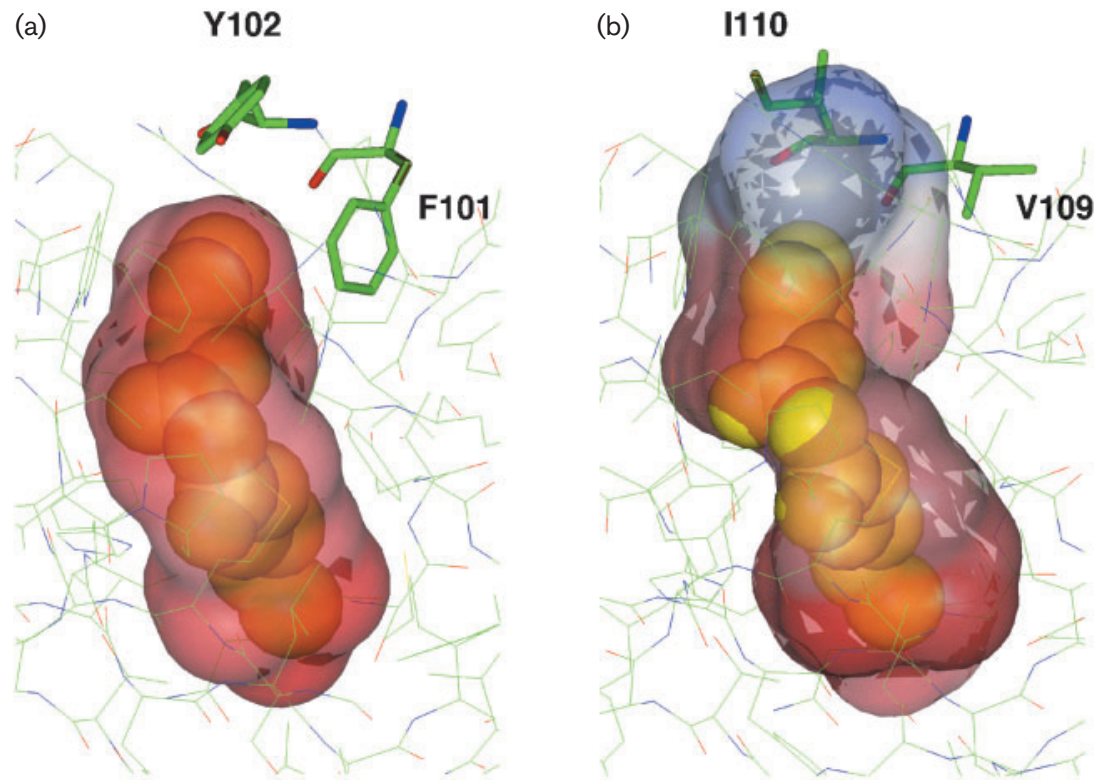

Fig. 3. The calculated size and shape of the binding site of (a) TraR and (b) the LuxR model obtained by molecular modelling. The van der Waals surface of the $\mathrm{OOHL}$ molecule in its observed binding mode in TraR is shown in yellow. Red on the calculated surface of the binding sites indicates highly buried (solvent excluded) binding site volumes, whereas blue indicates highly solvent accessible volumes. 
concentrations ranging from $1 \mathrm{nM}$ to $100 \mu \mathrm{M}$. The mutated LuxR proteins W66H, D79N, W94D, V109D and I110D were unable to mediate detectable GFP expression in the presence of $100 \mu \mathrm{M}$ OHHL (data not shown), and we therefore considered these proteins inactive. However, GFP expression could be induced from plasmids carrying the Y62F, V109T and I110T LuxR mutations by a 5000-10 000fold higher OHHL concentration than their wild-type counterpart (Fig. 4). The mutations D79N, W94Q and V109L have previously been shown to cause inactivation of LuxR (Slock et al., 1990; Shadel et al., 1990), as have point mutations in the residues corresponding to D79 in TraR (i.e. D70N/D70E) (Luo et al., 2003a) and LasR (D73E) (Kiratisin et al., 2002), and the residue corresponding to W94 (W88Y) in LasR (Kiratisin et al., 2002).

LuxR inactivation by amino acid changes in the $\mathrm{N}$-terminal region can be caused by misfolding or disruption of the structural integrity of the protein. Alternatively, it can be caused by disruption of essential subunit interactions, which would otherwise lead to dimerization, or by disruption of the interaction with OHHL. The amounts of LuxR and LuxR mutant proteins present in E. coli cells carrying pJBA89 with wild-type or mutated $\operatorname{luxR}$ genes varied to some extent between experiments as judged by Western blotting; however, only W94D was reproducibly found in very low amounts (Fig. 5). It has previously been observed that the W94 mutation (W94Q) in LuxR led to a low level of protein expression as judged from Western blotting (Slock et al., 1990). In this case the low level of protein could, however, be due to an inefficient amber suppression in the E. coli strain (Slock et al., 1990).

The AHL sensor pJBA89 responds to a variety of AHL molecules with side chains of six or more carbon atoms, but shows a very limited response to $\mathrm{N}$-butanoyl-L-homoserine lactone (BHL) (Andersen et al., 2001). Accordingly, Schaefer et al. (1996) reported that a minimum side chain length of five carbon atoms is required for binding to LuxR. For the LuxR mutants Y62F, V109T and I110T we tested for induction by the OHHL agonists $N$-hexanoyl-DLhomoserine lactone (HHL), N-octanoyl-DL-homoserine lactone (OHL), OOHL and BHL (for structures see Fig. 1). For the Y62F mutant all the agonists except BHL induced GFP expression. V109T and I110T failed to be induced by HHL, OHL and BHL, but were induced by OHHL and OOHL (Fig. 4). This indicates that the activation of the mutants V109T and I110T depends on the composition of the acyl side chain.

These results are hard to explain by assuming the orientation of the OHHL signal in the binding pocket of LuxR resembles the OOHL orientation in TraR. F101 in TraR (corresponding to V109 in LuxR) and Y102 in TraR (corresponding to I110 in LuxR) are distantly situated from the acyl side chain of the signal molecule in the TraR/OOHL complex. Furthermore, a Y53F mutation in TraR resulted in an almost inactive protein (Chai \& Winans, 2004), while the Y62F mutant of LuxR could be activated by all the tested signal molecules except
BHL. The presence of the bulky side chain of L42 in LuxR (Fig. 6) (corresponding to A38 in TraR) also argues against a similar positioning of the OHHL side chain in LuxR and the OOHL side chain in TraR, since the leucine residue at this position in LuxR would cause a reduction in the space available for the acyl side chain. The importance of a small amino acid residue at this position in TraR is highlighted by the observation that an A38V mutant of TraR was severely affected in signal-binding ability (Luo et al., 2003a).

We therefore propose the following model for LuxR signal binding as presented in Fig. 6. The LuxR residues Y62 and W66 correspond to Y53 and W57 in TraR, respectively. In both LuxR and TraR these residues form hydrogen bonds to the cognate signal molecule. D79 in LuxR corresponds to D70 in TraR. In both cases, this residue forms a hydrogen bond to the NH group of the signal molecule. The differences lie in the hydrogen bonds formed by the LuxR residues Y62 and W66, and in the positioning of the acyl side chain and thereby in the residues involved in the hydrophobic interactions with the side chain. In our proposed model for LuxR OHHL binding, Y62 forms a hydrogen bond to the lactone carbonyl group while W66 forms a hydrogen bond to the 1-carbonyl group of the acyl chain (Fig. 6). This is the opposite of TraR, where W57 forms a hydrogen bond to the lactone carbonyl group, and Y53 forms a hydrogen bond to the 1-carbonyl group of the acyl chain. Consequently, the orientation of the acyl chain must be flipped in LuxR such that V109 and I110 become involved in hydrophobic interaction with $\mathrm{C} 5 / \mathrm{C} 6$ of the acyl chain. These hydrophobic interactions might be necessary to position and fix the signal molecule in the LuxR binding pocket, since an acyl chain containing five carbon atoms or more is required for efficient LuxR binding (Schaefer et al., 1996). Activation of V109T and I110T by OHHL and OOHL, but not by HHL or OHL (Fig. 4) suggests that the threonine residue of the mutant proteins is able to interact with the $\mathrm{C}-3$ oxo group of OHHL and OOHL through a water-mediated hydrogen bond as shown in Fig. 6 .

This model can also explain the observed differences between the LuxR and TraR mutant proteins. Y62 forms a hydrogen bond to the ring carbonyl group, as does W57 of TraR (Zhang et al., 2002; Vannini et al., 2002). The TraR W57Y mutant shows activation patterns similar to the wildtype protein, while the $\mathrm{Y} 53 \mathrm{~F}$ mutant remains inactive (Chai \& Winans, 2004). The corresponding LuxR mutants showed the opposite behaviour. The $\mathrm{W} 66 \mathrm{H}$ mutant was inactive while the Y62F mutant could be fully activated although it required much higher signal concentrations than the wildtype. This difference may be caused by the significantly stronger hydrogen bond accepting capacity of the carbonyl oxygen present in the amide group, compared to a carbonyl oxygen of an ester group. Thus, the loss or change of hydrogen bond donation to an amide carbonyl oxygen, as in the LuxR mutant $\mathrm{W} 66 \mathrm{H}$ and the TraR mutant Y53F, might be expected to affect the ligand binding more seriously and thereby cause inactivation of the protein. 

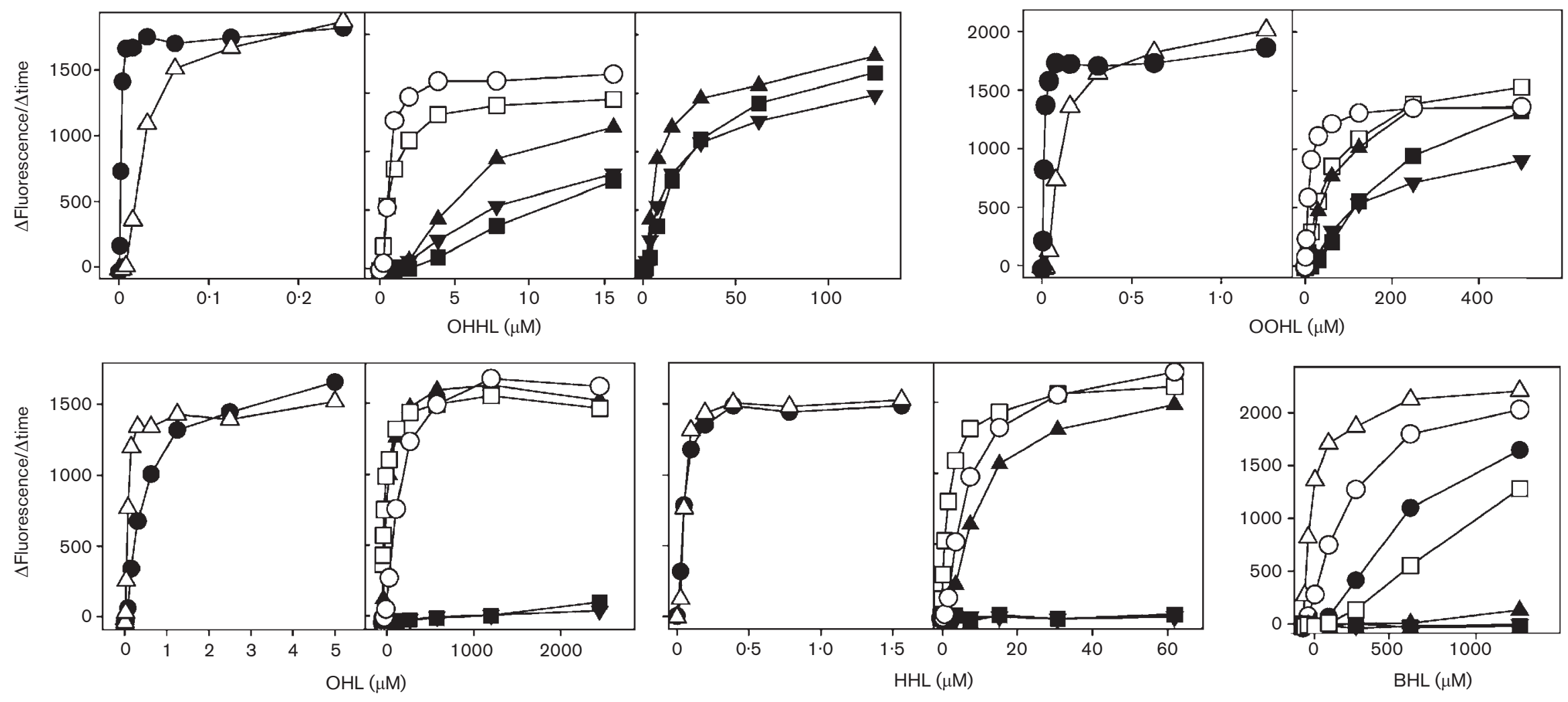

Fig. 4. Effects of LuxR mutations on LuxR activity. Dose response of GFP expression from E. coli XL1-Blue cells carrying pJBA89 encoding wild-type LuxR, or pJBA89 derivatives encoding mutated LuxR proteins, to different homoserine lactones. AHLs were added at time 0 , GFP expression and OD 450 were measured every $15 \mathrm{~min}$ for $2 \mathrm{~h}$. Each point on the curve represents the result from a linear regression of cell-specific fluorescence versus time. pJBA89; $\triangle$, L42A; O, L42S; $\mathbf{\Delta}$, Y62F; $\mathbf{\nabla}$, V109T; $\mathbf{\square}$, I110T; $\square$, M135A. 


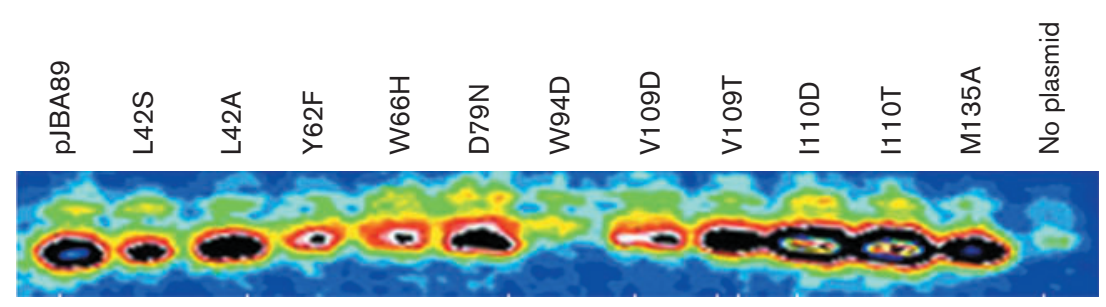

Fig. 5. Western blot of whole-cell extracts of $E$. coli XL1-Blue cells harbouring pJBA89 encoding wild-type LuxR or pJBA89 derivatives encoding mutant LuxR proteins, or no plasmid. The colours reflect the intensity of the bands, which correlates with protein quantity. The highest band intensity is represented by black with white, red, green, yellow and blue representing decreasing intensity, respectively.

A38 of TraR is situated near the acyl chain of the signal molecule (Zhang et al., 2002; Vannini et al., 2002), while the corresponding LuxR residue L42 in our model is closer to the homoserine lactone moiety of the signal molecule (Fig. 6). To further test the model, the mutants L42A and L42S were constructed. L42A was fully activated by a 15 -fold higher OHHL concentration than the wild-type LuxR (Fig. 4), while L42S required 1000-fold higher concentrations. Similar results were obtained for OOHL activation.

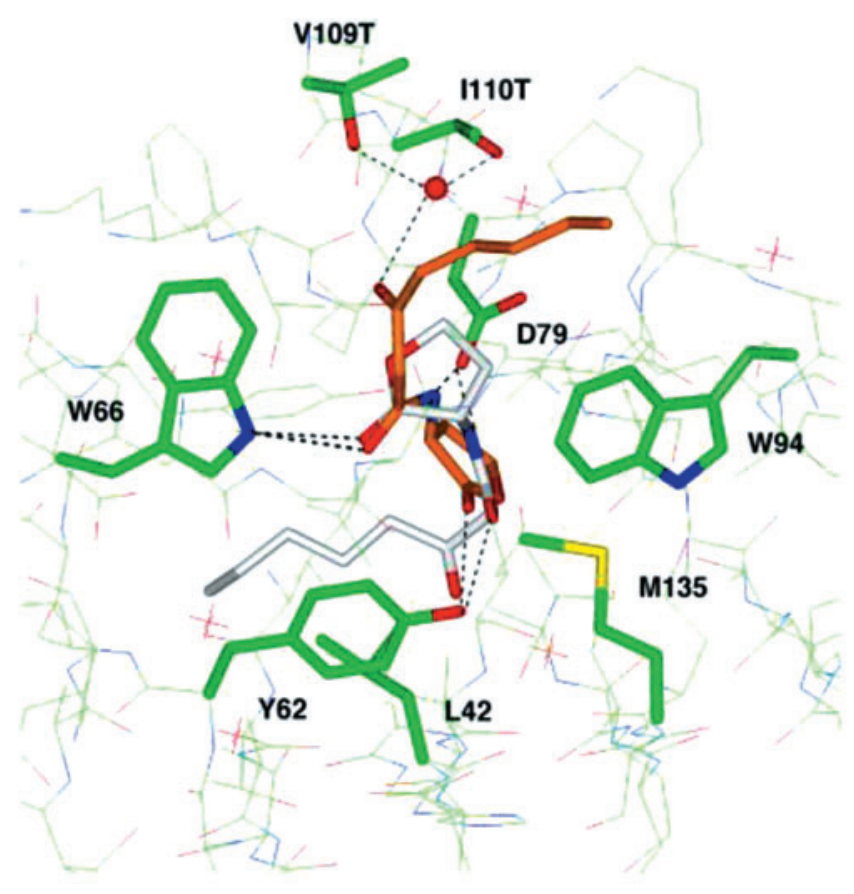

Fig. 6. A proposed model for the LuxR binding site and the binding mode of $\mathrm{OOHL}$ in this site. $\mathrm{OOHL}$ in the suggested binding mode in LuxR is shown with orange carbon atoms, whereas $\mathrm{OOHL}$ in the observed binding mode in TraR is shown with white carbon atoms. Hydrogen bonds are shown as dashed lines. The model also illustrates the possibility that the 3-oxo group in $\mathrm{OOHL}$ interacts via a water-mediated hydrogen bond to the LuxR mutants V109T and I110T. The proposed water molecule is shown as a red sphere. To obtain the $3-D$ model the amino acids within the sphere surrounding the binding site of the TraR crystal structure were changed to LuxR amino acids.
For OHL and HHL, equal or slightly lower concentrations were required for activation of $\mathrm{L} 42 \mathrm{~A}$, while $\mathrm{L} 42 \mathrm{~S}$ required 100-500-fold higher concentrations than the wild-type (Fig. 4). In comparison, the A38V mutation of TraR led to more pronounced effects: the mutant protein responded to OOHL at concentrations similar to the wild-type but could only attain half the activity of the wild-type protein, and was substantially less sensitive to OHL and OHHL indicating a role of the AHL side chain in the activity of this mutant (Luo et al., 2003a). A remarkable difference between L42A and L42S mutants and the wild-type was observed with BHL (Fig. 4), which activated L42A and L42S. The short hydrocarbon chain of BHL makes it less probable that this compound can bind to LuxR in the mode that we have proposed for OHHL and OOHL (Fig. 6), due to lack of hydrophobic interaction between BHL and V109/I110. Thus, BHL most probably binds in a mode similar to that of OOHL in TraR (Fig. 6). This makes BHL binding to the wild-type protein weaker due to steric repulsive interactions with L42. The L42A and L42S mutations should relieve these steric repulsions due to the significantly smaller size of alanine and serine compared to that of leucine (Fig. 7). Our proposed binding mode for BHL is also supported by the observation that BHL, in contrast to all the other tested signal molecules, cannot activate the Y62F mutant (Fig. 4). As mentioned above, the corresponding Y53F mutant in TraR is almost inactive.

If the binding of the signal molecule differs between LuxR and TraR, TraR might be a poor model for the prediction of residues involved in the interaction with halogenated furanones. Therefore, residue M135 was selected for mutagenesis, which according to the large accessible space in the vicinity of M135 in the binding site of the LuxR model (Fig. 6) may be close to the one bromine atom of the halogenated furanones. The M135A mutant could be activated by all the tested AHLs, although it required much higher concentrations compared to the wild-type counterpart (Fig. 4).

\section{Interactions between signal analogues, LuxR and LuxR mutants}

Much of the effort directed towards construction of quorum-sensing inhibitors has focused on the synthesis of compounds that resemble the signal molecules and can serve as competitive inhibitors (Smith et al., 2003; Olsen et al., 


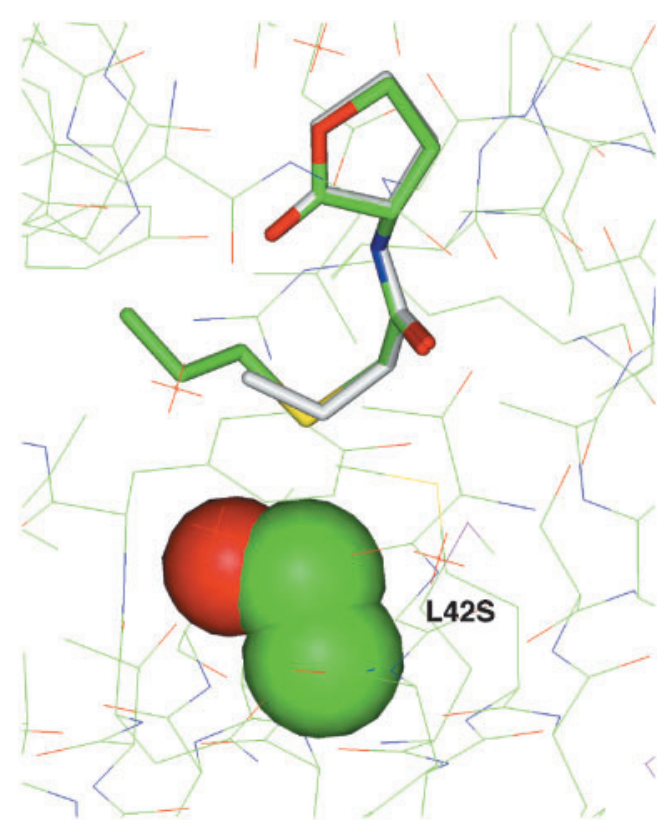

Fig. 7. A molecular superimposition of $\mathrm{BHL}$ (white carbon atoms) and ProS-AHL (green carbon atoms) in their proposed binding modes in the LuxR mutant L42S.

2002; Persson et al., 2005). The compounds ProS-AHL and PenS-AHL (Fig. 1) differ from OHHL and OOHL, respectively, in the substitution of a carbonyl group with a sulfur atom, and differ from HHL and OHL by the replacement of a $\mathrm{CH}_{2}$ group with a sulfur atom. The significantly smaller size of a sulfur atom compared to a carbonyl group, the different geometries of the C-S-C and $\mathrm{C}-\mathrm{C}-\mathrm{C}$ moieties, and the higher degree of polarization of a sulfur atom compared to a $\mathrm{CH}_{2}$ group influence the steric properties and thereby the ability of the molecules to fit into the signal-binding cavity. This might explain the ability of the sulfur analogues to serve as quorum-sensing inhibitors.

To determine the ability of ProS-AHL and PenS-AHL to inhibit LuxR-controlled GFP expression, cells carrying pJBA89 were incubated with a saturating amount of OHHL (i.e. $5 \mathrm{nM}$ ) and varying concentrations of ProSAHL or PenS-AHL. Full inhibition of GFP expression was obtained with approximately $10 \mu \mathrm{M}$ ProS-AHL (Fig. 8a), while approximately $100 \mu \mathrm{M}$ PenS-AHL was needed to obtain full inhibition (data not shown). To examine the agonist activity at high concentrations, cells carrying pJBA89 were incubated with varying amounts of ProS-AHL. At high concentrations, addition of ProS-AHL stimulated a low level of GFP expression (Fig. 8b). To determine the extent to which the introduced mutations in LuxR influenced the antagonist and agonist activity of ProS-AHL, a selection of LuxR mutants (which could be activated by OHHL) were incubated with ProS-AHL in the absence or presence of saturating amounts of OHHL (i.e. $5 \mathrm{nM}$ for pJBA89, $75 \mathrm{nM}$ for pJBA89L42A, $5 \mu \mathrm{M}$ for pJBA89L42S and pJBA89M135A, $30 \mu \mathrm{M}$ for pJBA89Y62F and $60 \mu \mathrm{M}$ for pJBA89V109T and pJBA89I110T). Changes in GFP expression per unit time were recorded. In the antagonist assay (Fig. 8a) expression of GFP in the presence of only OHHL was arbitrarily defined as $100 \%$ activity. As shown in Fig. 8(a), all six mutations rendered the protein insensitive to inhibition by ProS-AHL, indicating that the mutations have a larger impact on the binding of ProS-AHL than on the binding of OHHL. For Y62F, V109T, I110T and M135A the agonist activity of ProS-AHL was less than for the wildtype (Fig. 8b). In contrast, ProS-AHL served efficiently as an agonist for L42A and L42S (Fig. 8b). Similarly to BHL, we propose that the L42A and L42S mutations enable
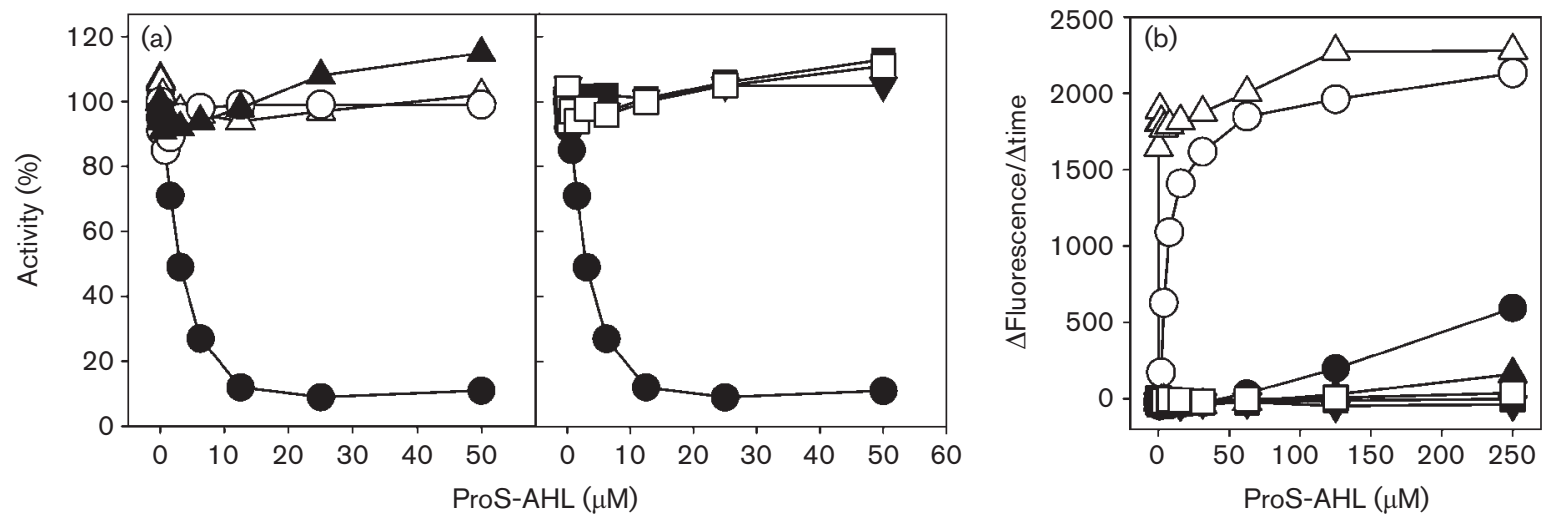

Fig. 8. The $A H L$ analogue ProS-AHL as antagonist and agonist. (a) Effect of ProS-AHL on LuxR-regulated GFP expression at saturating $\mathrm{OHHL}$ concentrations. Each point on the curves represents the result from a linear regression of cell-specific fluorescence versus time. Changes in fluorescence versus time in the absence of ProS-AHL were defined as $100 \%$. (b) Induction of LuxR-regulated GFP expression by ProS-AHL. E. coli XL1-Blue harbouring pJBA89 encoding wild-type LuxR, or pJBA89 derivatives encoding mutated LuxR proteins, was used. Each point on the curve represents the result from a linear regression of cell-specific fluorescence versus time. ๑, pJBA89; $\triangle$, L42A; O, L42S; $\mathbf{\Delta}$, Y62F; $\mathbf{\nabla}$, V109T; $\mathbf{\square}$, I110T; $\square$, M135A. 
ProS-AHL to bind to LuxR in an 'OOHL-TraR-like mode' (Fig. 7).

\section{Interactions between halogenated furanones and the LuxR mutants}

To determine whether the LuxR mutations would also lead to more tolerance towards the action of halogenated furanones, we compared the ability of the two natural compounds C-2 and C-4, and the synthetic C-30, to inhibit GFP expression from E. coli harbouring either pJBA89, pJBA89L42A, pJBA89L42S, pJBA89Y62F, pJBA89V109T, pJBA89I110T or pJBA89M135A (for structures of the furanones see Fig. 1). The compounds were added simultaneously with a saturating amount of OHHL. Changes in GFP expression per unit time at 12 different furanone concentrations were determined. GFP expression in the presence of OHHL and no furanone was arbitrarily defined as $100 \%$ activity. As shown in Fig. 9, the mutants L42A, L42S and V109T were significantly less sensitive towards furanone C-2 and C-4 compared to the wild-type under similar conditions, in contrast to the remaining mutants. Surprisingly, all mutants except L42A showed more sensitivity than the wild-type towards furanone C-30 treatment (Fig. 9). These data might indicate a difference in the binding mode of natural and synthetic halogenated furanones, the latter furanones being devoid of the side chain present in the natural compounds. However, compared to ProS-AHL the LuxR mutations had a very limited impact on the sensitivity to treatment with halogenated furanones.

The hallmark of competitive enzyme inhibition is that it can be overcome by a sufficiently high concentration of substrate. It was originally shown that the effect of furanones $\mathrm{C}-1$ and $\mathrm{C}-2$ on S. liquefaciens swarming could be relieved by increasing amounts of BHL (Givskov et al., 1996). Due to the structural similarity between AHLs and halogenated furanones this led to the hypothesis that these compounds affected quorum sensing by competitively binding to the signal binding sites of LuxR-type proteins (Givskov et al., 1996). It was later shown by Western blotting that halogenated furanones accelerate the turnover of LuxR (Manefield et al., 2002). This would account for the observation that the presence of halogenated furanones reduced the binding of $\left[{ }^{3} \mathrm{H}\right] \mathrm{OHHL}$ to $E$. coli cells overexpressing LuxR (Manefield et al., 1999). Accordingly, a stable complex between a tritiated halogenated furanone and LuxR could not be detected in similar experimental settings (Manefield et al., 2002), but it provided no answer to the question as to whether halogenated furanones would fit into the OHHL-binding cavity.

Using the LuxR-based AHL monitor strain E. coli MT102(pSB403) it was shown that inhibition by $100 \mu \mathrm{M}$ C-2 could be relieved by addition of $100 \mathrm{nM}$ OHHL while the inhibition by $50 \mu \mathrm{M} \mathrm{C}-4$ could not (Manefield et al., 1999). To re-examine the AHL-offered protection, we carried out a series of experiments with E. coli XL1Blue(pJBA89) in which we investigated whether a surplus of
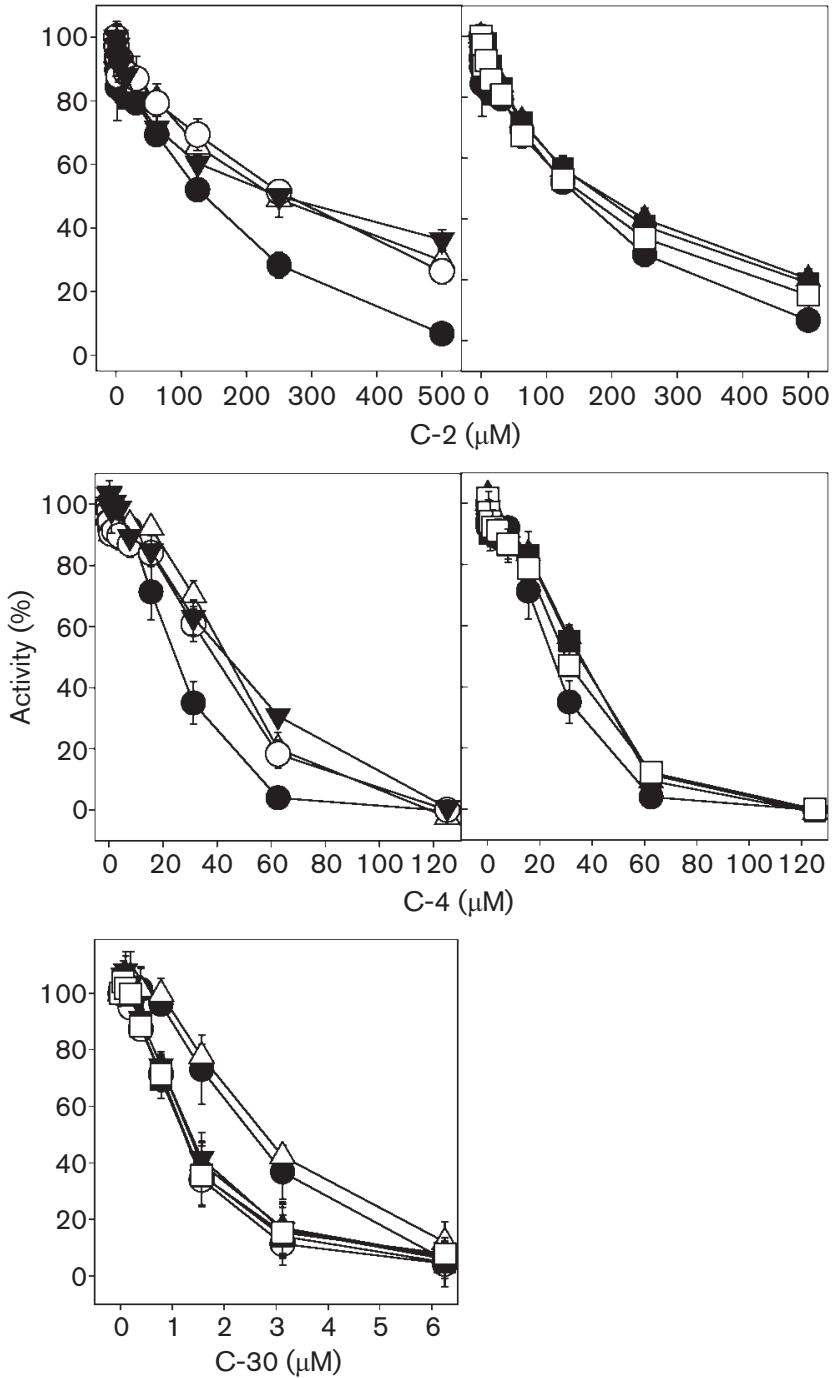

Fig. 9. Effects of LuxR mutations on the sensitivity of LuxR towards halogenated furanones. GFP expression from $E$. coli XL1-Blue cells harbouring pJBA89 encoding wild-type LuxR, or pJBA89 derivatives encoding mutated LuxR proteins, were treated with varying concentrations of $\mathrm{C}-2, \mathrm{C}-4$ or $\mathrm{C}-30$ at saturating $\mathrm{OHHL}$ concentrations. Each point on the curve represents the result from a linear regression of cell-specific fluorescence versus time. Changes in fluorescence versus time in the absence of halogenated furanones were defined as $100 \%$. The data shown are mean values from three independent experiments. Error bars indicate SDs. - pJBA89; $\triangle$, L42A; $\bigcirc$, L42S; $\boldsymbol{\Delta}$, Y62F; $\boldsymbol{\nabla}$, V109T; $\mathbf{\square}$, I110T; $\square$, M135A.

OHHL would allow LuxR to activate $P_{l u x I}$ in the presence of furanone compounds. In all cases, addition of OHHL had an effect. However, while all of the inhibition exerted by $\mathrm{C}-2$ treatment and most of the inhibition exerted by C-4 treatment could be reversed by the addition of $50 \mathrm{nM}$ OHHL, C-56 and C-30 required concentrations in the micromolar range (Fig. 10). Furthermore, while full protection could be achieved against C-2 (50 nM OHHL 


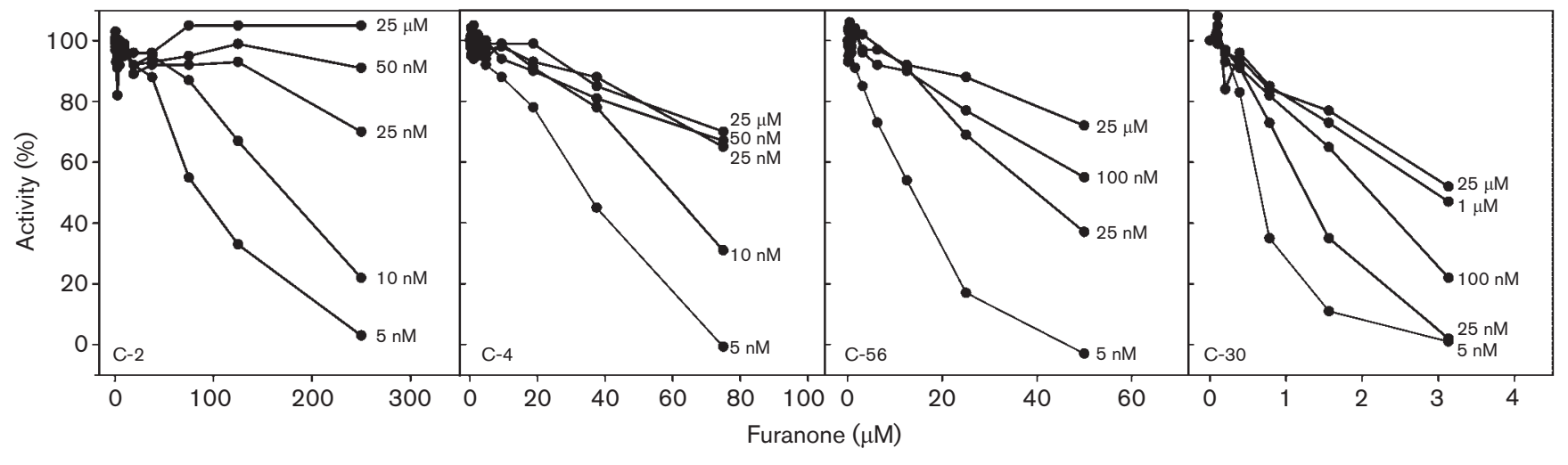

Fig. 10. OHHL-mediated protection of LuxR against halogenated furanones. The effect is shown of halogenated furanones C-2, C-4, C-56 and C-30 on LuxR-regulated GFP expression in E. coli XL1-Blue(pJBA89) cells at OHHL concentrations ranging from $5 \mathrm{nM}$ to $25 \mu \mathrm{M}$. Each point on the curve represents the result from a linear regression of cell-specific fluorescence versus time. Changes in fluorescence versus time in the absence of halogenated furanones were defined as $100 \%$.

against $250 \mu \mathrm{M} \mathrm{C}-2$ ), only approximately $50 \%$ protection could be obtained for C-30 (25 $\mu \mathrm{M}$ OHHL against $3 \mu \mathrm{M}$ C-30).

The LuxR expression plasmid pHK724 carrying the luxR gene under control of the $P_{t a c}$-promoter (Hanzelka \& Greenberg, 1995) has previously been used to study degradation of LuxR (Manefield et al., 2002). These experiments showed that addition of $2 \mu \mathrm{M}$ OHHL prior to the addition of $10 \mu \mathrm{M}$ furanone $\mathrm{C}-30$ caused a delay in degradation by approximately $10 \mathrm{~min}$. In similar experiments, $E$. coli XL1-Blue(pHK724)(pGroESL) was treated with C-2 or $\mathrm{C}-30$, and exposed to varying concentrations of OHHL. The furanones and OHHL were added simultaneously to exponentially growing cells (which were washed free of IPTG prior to the additions) and the treatments were stopped after $1 \mathrm{~h}$ by freezing the samples. The amounts of LuxR protein in the samples were then visualized by analysis of Western blots using LuxR antibodies according to Manefield et al. (2002). For furanone C-2, a concentration-dependent OHHL protection could be observed (Fig. 11a). For furanone C-30, no significant level of protection was observed after addition of $25 \mu \mathrm{M}$ OHHL (Fig. 11b). This is consistent with the data presented in Fig. 10.

Although the addition of AHL molecules was able to prevent LuxR degradation by the natural furanone $\mathrm{C}-2$, we cannot conclude that the furanones bind to the signal-binding cavity. Our mutant protein data show that mutations in the LuxR residues Y62 and M135 do not lead to tolerance to halogenated furanones. This indicates that these residues are not situated close to the site where halogenated furanones interact with LuxR, and therefore the receptor site for the furanone compounds may be positioned differently from the signal-binding cavity. Based on the data presented in Fig. 10, we also propose that this putative receptor site exhibits different affinities for the furanone compounds,
C-2 having the lowest affinity, then in increasing order of affinity C-4, C-56 and C-30. Furthermore, the various degrees of protection offered by OHHL may be explained if one assumes that binding of the signal molecule leads to a conformational change in LuxR, which in turn reduces the affinity for furanone binding. More work is required to elucidate the precise mechanism for quorum-sensing inhibition by the furanones but the present data, as well as previous data (Manefield et al., 2002), strongly suggest that it is not a 'classic' competition for the OHHL-binding cavity.

\section{Perspective}

The development of bacterial resistance to antibiotics is a serious side-effect of current anti-microbial treatments. The alternative to antibiotic-mediated killing or growth inhibition is to attenuate bacterial virulence such that the organism fails to establish a successful infection, and as a consequence is cleared by the host immune response. Specific targets for future anti-microbial drugs are likely to be key regulatory functions governing control over bacterial virulence, surface colonization and biofilm development. A major advantage of this strategy is that it most likely circumvents the problem of resistance, which is intimately connected to the use of conventional anti-bacterial agents. Examples of this are quorum-sensing inhibitors, which in contrast to the traditional anti-microbial agents can be used in low, sub-growth-inhibitory doses (Hentzer et al., 2003). In the present study we have performed site-directed mutagenesis of the signal binding site of LuxR to gain insight into the mechanism of inhibition and particularly the development of resistance towards quorum-sensing inhibitors. This analysis illustrates the lack of X-ray crystallographic data to support positioning of the OHHL signal molecule in the LuxR-binding cavity. Until that is achievable, we propose a model that flips the acyl side chain in the LuxR/signal 


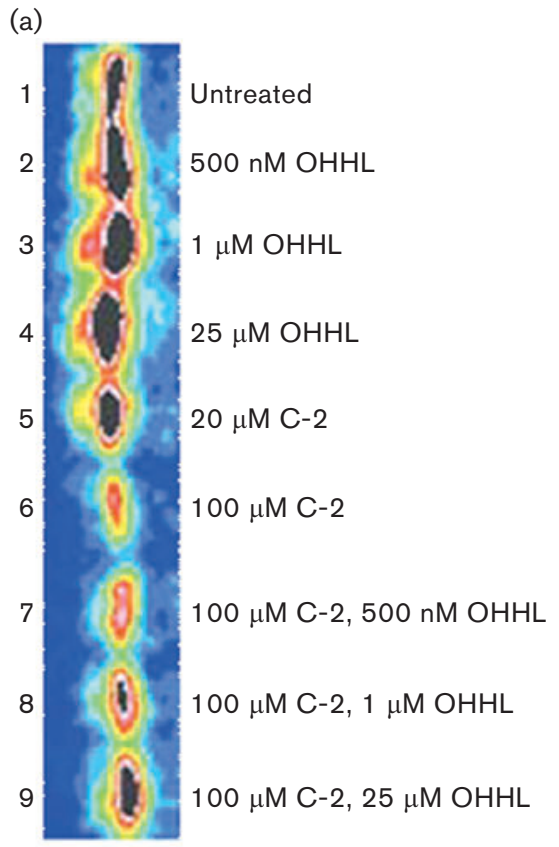

(b)

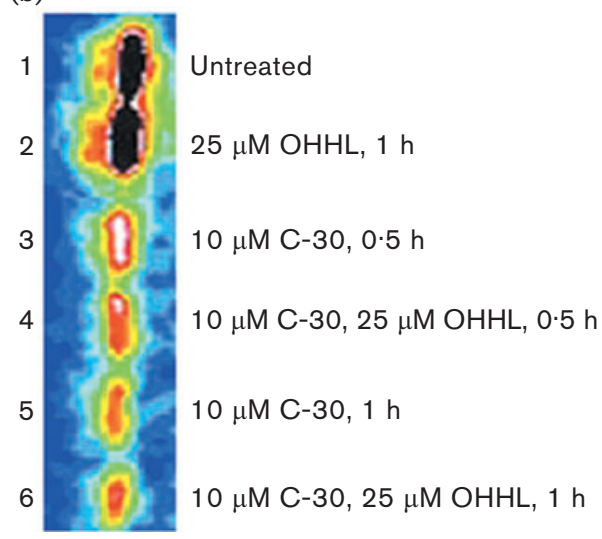

Fig. 11. OHHL-mediated protection of LuxR against halogenated furanones. The Western blots show the effect of increasing $\mathrm{OHHL}$ concentrations on the decay of LuxR in E. coli XL1Blue(pHK724)(pGroESL) cells after the addition of furanone C-2 (a) and furanone C-30 (b). (a) Lane 1, untreated control; lane 2-lane 9 cells treated with $\mathrm{OHHL}$ and/or furanone $\mathrm{C}-2$ for $1 \mathrm{~h}$ as indicated in the figure. (b) Lane 1, untreated control; lanes 2-6, cells treated with $\mathrm{OHHL}$ and/or furanone $\mathrm{C}-30$ for 1 or $0.5 \mathrm{~h}$ as indicated in the figure. The colours reflect the intensity of the band, which correlates with protein quantity. The highest band intensity is represented by black with white, red, green, yellow and blue representing decreasing intensity, respectively.

molecule complex compared to the TraR/signal molecule complex.

Interestingly, point mutations in the signal binding site rendered LuxR insensitive to the activity of the synthetic inhibitor ProS-AHL. Are such mutant proteins also insensitive to OHHL activation and are cells harbouring such quorum sensors unable to signal each other? Not necessarily, one of these mutants could be activated in the presence of a 15-fold higher concentration of OHHL (compared to the concentration required to fully activate the wild-type protein). Although there is no selective pressure imposed by the inhibitors per se, it is conceivable that pathogenic bacteria in the long run might develop resistance to quorum-sensing inhibitors that are based on agonist structure. In contrast, our furanone analysis suggests that through time inhibitors have been selected in nature where single amino acid changes in a separated receptor site leading to resistance are less likely to occur. This highlights the importance of screening natural libraries for identification of quorumsensing inhibitors, which might provide scaffolds for the development of powerful synthetic anti-microbial drugs.

\section{ACKNOWLEDGEMENTS}

A. B. Christensen, J. B. Andersen, M. E. Skindersøe and M. Hentzer are thanked for helpful discussions. Linda Stabell and Anne Nielsen are thanked for excellent technical assistance. This work was supported by grants from the Villum Kann Rasmussen Foundation and the Danish Technical Research Council to M. Givskov.

\section{REFERENCES}

Andersen, J. B., Heydorn, A., Hentzer, M., Eberl, L., Geisenberger, O., Christensen, B. B., Molin, S. \& Givskov, M. (2001). gfp-based $\mathrm{N}$-acyl homoserine-lactone sensor systems for detection of bacterial communication. Appl Environ Microbiol 67, 575-585.

Atkinson, S., Throup, J. P., Stewart, G. S. \& Williams, P. (1999). A hierarchical quorum-sensing system in Yersinia pseudotuberculosis is involved in the regulation of motility and clumping. Mol Microbiol 33, 1267-1277.

Bauer, W. D. \& Robinson, J. B. (2002). Disruption of bacterial quorum sensing by other organisms. Curr Opin Biotechnol 13, 234-237.

Brady, G. P., Jr \& Stouten, P. F. (2000). Fast prediction and visualization of protein binding pockets with PASS. J Comput Aided Mol Des 14, 383-401.

Cha, C., Gao, P., Chen, Y. C., Shaw, P. D. \& Farrand, S. K. (1998). Production of acyl-homoserine lactone quorum-sensing signals by Gram-negative plant-associated bacteria. Mol Plant Microbe Interact 11, 1119-1129.

Chai, Y. \& Winans, S. C. (2004). Site-directed mutagenesis of a LuxRtype quorum-sensing transcription factor: alteration of autoinducer specificity. Mol Microbiol 51, 765-776.

Choi, S. H. \& Greenberg, E. P. (1991). The C-terminal region of the Vibrio fischeri LuxR protein contains an inducer-independent lux gene activating domain. Proc Natl Acad Sci U S A 88, 11115-11119.

Christensen, A. B., Riedel, K., Eberl, L., Flodgaard, L. R., Molin, S., Gram, L. \& Givskov, M. (2003). Quorum-sensing-directed protein expression in Serratia proteamaculans B5a. Microbiology 149, 471-483.

Clark, J. D. \& Maaløe, O. (1967). DNA replication and the division cycles in Escherichia coli. J Mol Biol 23, 99-112.

de Nys, R., Wright, A., Konig, G. M. \& Sticher, O. (1993). New halogenated furanones from the marine alga Delisea pulchra (cf. Fimbriata). Tetrahedron 49, 11213-11220. 
Givskov, M., de Nys, R., Manefield, M., Gram, L., Maximilien, R., Eberl, L., Molin, S., Steinberg, P. D. \& Kjelleberg, S. (1996). Eukaryotic interference with homoserine lactone-mediated prokaryotic signalling. J Bacteriol 178, 6618-6622.

Goloubinoff, P., Gatenby, A. A. \& Lorimer, G. H. (1989). GroE heatshock proteins promote assembly of foreign prokaryotic ribulose bisphosphate carboxylase oligomers in Escherichia coli. Nature 337, 44-47.

Hanzelka, B. L. \& Greenberg, E. P. (1995). Evidence that the Nterminal region of the Vibrio fischeri LuxR protein constitutes an autoinducer-binding domain. J Bacteriol 177, 815-817.

Hentzer, M., Riedel, K., Rasmussen, T. B. \& 9 other authors (2002). Inhibition of quorum sensing in Pseudomonas aeruginosa biofilm bacteria by a halogenated furanone compound. Microbiology 148, 87-102.

Hentzer, M., Wu, H., Andersen, J. B. \& 15 other authors (2003). Attenuation of Pseudomonas aeruginosa virulence by quorum sensing inhibitors. EMBO J 22, 3803-3815.

Ho, S. N., Hunt, H. D., Horton, R. M., Pullen, J. K. \& Pease, L. R. (1989). Site-directed mutagenesis by overlap extension using the polymerase chain reaction. Gene 77, 51-59.

Kaplan, H. B. \& Greenberg, E. P. (1987). Overproduction and purification of the luxR gene product: transcriptional activator of the Vibrio fischeri luminescence system. Proc Natl Acad Sci U S A 84, 6639-6643.

Kiratisin, P., Tucker, K. D. \& Passador, L. (2002). LasR, a transcriptional activator of Pseudomonas aeruginosa virulence genes, functions as a multimer. J Bacteriol 184, 4912-4919.

Lamb, J. R., Patel, H., Montminy, T., Wagner, V. E. \& Iglewski, B. H. (2003). Functional domains of the RhlR transcriptional regulator of Pseudomonas aeruginosa. J Bacteriol 185, 7129-7139.

Luo, Z. Q., Smyth, A. J., Gao, P., Qin, Y. \& Farrand, S. K. (2003a). Mutational analysis of TraR. Correlating function with molecular structure of a quorum-sensing transcriptional activator. J Biol Chem 278, 13173-13182.

Luo, Z. Q., Su, S. \& Farrand, S. K. (2003b). In situ activation of the quorum-sensing transcription factor TraR by cognate and noncognate acyl-homoserine lactone ligands: kinetics and consequences. J Bacteriol 185, 5665-5672.

Manefield, M., de Nys, R., Kumar, N., Read, R., Givskov, M., Steinberg, P. \& Kjelleberg, S. (1999). Evidence that halogenated furanones from Delisea pulchra inhibit acylated homoserine lactone (AHL)-mediated gene expression by displacing the AHL signal from its receptor protein. Microbiology 145, 283-291.

Manefield, M., Harris, L., Rice, S. A., de Nys, R. \& Kjelleberg, S. (2000). Inhibition of luminescence and virulence in the black tiger prawn (Penaeus monodon) pathogen Vibrio harveyi by intercellular signal antagonists. Appl Environ Microbiol 66, 2079-2084.

Manefield, M., Welch, M., Givskov, M., Salmond, G. P. \& Kjelleberg, S. (2001). Halogenated furanones from the red alga, Delisea pulchra, inhibit carbapenem antibiotic synthesis and exoenzyme virulence factor production in the phytopathogen Erwinia carotovora. FEMS Microbiol Lett 205, 131-138.

Manefield, M., Rasmussen, T. B., Henzter, M., Andersen, J. B., Steinberg, P., Kjelleberg, S. \& Givskov, M. (2002). Halogenated furanones inhibit quorum sensing through accelerated LuxR turnover. Microbiology 148, 1119-1127.

Manny, A. J., Kjelleberg, S., Kumar, N., de Nys, R., Read, R. \& Steinberg, P. (1997). Reinvestigation of the sulfuric acid-catalysed cyclisation of brominated 2-alkyllevulinic acids to 3-alkyl-5-methylene-2(5H)furanones. Tetrahedron 53, 15813-15826.
Marketon, M. M., Gronquist, M. R., Eberhard, A. \& Gonzales, J. E. (2002). Characterization of the Sinorhizobium meliloti $\sin R / \sin I$ locus and the production of novel $\mathrm{N}$-acyl homoserine lactone. J Bacteriol 184, 5686-5695.

Martinelli, D., Grossmann, G., Séquin, U., Brandl, H. \& Bachofen, R. (2004). Effects of natural and chemically synthesized furanones on quorum sensing in Chromobacterium violaceum. BMC Microbiol 4, 25.

Medina, G., Juarez, K., Valderrama, B. \& Soberon-Chavez, G. (2003). Mechanism of Pseudomonas aeruginosa RhlR transcriptional regulation of the rhlAB promoter. J Bacteriol 185, 5976-5983.

Minogue, T. D., Wehland-von Trebra, M., Bernhard, F. \& von Bodman, S. B. (2002). The autoregulatory role of EsaR, a quorum-sensing regulator in Pantoea stewartii ssp. stewartii: evidence for a repressor function. Mol Microbiol 44, 1625-1635.

Olsen, J. A., Severinsen, R., Rasmussen, T. B., Hentzer, M., Givskov, M. \& Nielsen, J. (2002). Synthesis of new 3- and 4-substituted analogues of acyl homoserine lactone quorum sensing autoinducers. Bioorg Med Chem Lett 12, 325-328.

Persson, T., Hansen, T. H., Rasmussen, T. B., Skindersøe, M. E., Givskov, M. \& Nielsen, J. (2005). Rational design and synthesis of new quorum-sensing inhibitors derived from acylated homoserine lactones and natural products from garlic. Org Biomol Chem 3, 253-262.

Sambrook, J., Fritsch, E. F. \& Maniatis, T. (1989). Molecular Cloning: a Laboratory Manual, 2nd edn. Cold Spring Harbor, NY: Cold Spring Harbor Laboratory.

Schaefer, A. L., Hanzelka, B. L., Eberhard, A. \& Greenberg, E. P. (1996). Quorum sensing in Vibrio fischeri: probing autoinducerLuxR interactions with autoinducer analogs. $J$ Bacteriol 178, 2897-2901.

Schuster, M., Lostroh, C. P., Ogi, T. \& Greenberg, E. P. (2003). Identification, timing, and signal specificity of Pseudomonas aeruginosa quorum-controlled genes: a transcriptome analysis. J Bacteriol 185, 2066-2079.

Shadel, G. S., Young, R. \& Baldwin, T. O. (1990). Use of regulated cell lysis in a lethal genetic selection in Escherichia coli: identification of the autoinducer-binding region of the LuxR protein from Vibrio fischeri ATCC 7744. J Bacteriol 172, 3980-3987.

Slock, J., VanRiet, D., Kolibachuk, D. \& Greenberg, E. P. (1990). Critical regions of the Vibrio fischeri LuxR protein defined by mutational analysis. J Bacteriol 172, 3974-3979.

Smith, R. S. \& Iglewski, B. H. (2003). P. aeruginosa quorum-sensing systems and virulence. Curr Opin Microbiol 6, 56-60.

Smith, K. M., Bu, Y. \& Suga, H. (2003). Induction and inhibition of Pseudomonas aeruginosa quorum sensing by synthetic autoinducer analogs. Chem Biol 10, 81-89.

Urbanowski, M. L., Lostroh, C. P. \& Greenberg, E. P. (2004). Reversible acyl-homoserine lactone binding to purified Vibrio fischeri LuxR protein. J Bacteriol 186, 631-637.

Vannini, A., Volpari, C., Gargioli, C., Muraglia, E., Cortese, R., De Francesco, R., Neddermann, P. \& Marco, S. D. (2002). The crystal structure of the quorum sensing protein TraR bound to its autoinducer and target DNA. EMBO J 21, 4393-4401.

Wagner, V. E., Bushnell, D., Passador, L., Brooks, A. I. \& Iglewski, B. H. (2003). Microarray analysis of Pseudomonas aeruginosa quorum-sensing regulons: effects of growth phase and environment. J Bacteriol 185, 2080-2095.

Wells, P. R. (1963). Enol lactones of dibromoacetylacrylic acid. Aust J Chem 16, 165-169.

Whitehead, N. A., Barnard, A. M., Slater, H., Simpson, N. J. \& Salmond, G. P. (2001). Quorum-sensing in Gram-negative bacteria. FEMS Microbiol Rev 25, 365-404. 
Whitehead, N. A., Byers, J. T., Commander, P. \& 11 other authors (2002). The regulation of virulence in phytopathogenic Erwinia species: quorum sensing, antibiotics and ecological considerations. Antonie van Leeuwenhoek 81, 223-231.

Zhang, R. G., Pappas, T., Brace, J. L. \& 7 other authors (2002). Structure of a bacterial quorum-sensing transcription factor complexed with pheromone and DNA. Nature 417, 971-974.
Zhu, J. \& Winans, S. C. (1999). Autoinducer binding by the quorumsensing regulator TraR increases affinity for target promoters in vitro and decreases TraR turnover rates in whole cells. Proc Natl Acad Sci U S A 96, 4832-4837.

Zhu, J., Beaber, J. W., More, M. I., Fuqua, C., Eberhard, A. \& Winans, S. C. (1998). Analogs of the autoinducer 3-oxooctanoyl-homoserine lactone strongly inhibit activity of the TraR protein of Agrobacterium tumefaciens. J Bacteriol 180, 5398-5405. 